\title{
Conceptos complejos: amor y estética
}

Por Carolina Aldaco Romero

Alumna de la Licenciatura en Música

\section{Introducción}

Desde la perspectiva de sujeto contemporáneo analizaré las relaciones entre los textos "Simposio (Banquete) o de la erótica" de Platón y "El Complejo de Amor" de Edgar Morin, que tratan precisamente del amor. También, explicaré con qué posturas de los integrantes del Banquete se relaciona más Edgar Morin. De igual manera, abordaré la relación entre los problemas encontrados en el texto "Simposio (Banquete) o de la erótica" en referencia al amor y el texto "Aesthetics" de Marc Jimenez, en referencia a la Estética. "La iluminación aclara las cosas pero al mismo tiempo revela aquello que se resiste a la luz, es decir, revela lo oscuro" (Morin, 1997, p. 1). Como sujeto contemporáneo con una sensibilidad contemporánea, puedo ver la oscuridad entre las luces de la época ${ }^{1}$. En este caso, eso me permite ver los problemas en las posturas de los filósofos que fueron invitados al Banquete y señalar las razones por las cuales Diotima y Edgar Morin están en lo correcto respecto a la complejidad del amor. Asimismo, puedo notar la similitud con los problemas de las posturas de los filósofos del texto de Jimenez y cómo, el concepto de estética es tan complejo como el concepto de amor.

\section{Problema con el complejo de amor}

En "Simposio (Banquete) o de la erótica", cada uno de los presentes hablan del concepto amor, lo definen y describen las características que consideran más adecuadas para explicarlo. Lo que ellos dijeron fue muy específico, como viendo el tema del amor como algo pequeño y sencillo.

Todas las definiciones de amor, señaladas en el Banquete, podrían complementarse para acercarse a una explicación más detallada y precisa. Sin embargo, el autor de "El complejo de amor" concuerda con la idea de Diotima del "Banquete" de que el tema del amor es mucho más amplio y complejo.

El amor es complejo o, más bien, hay un complejo de amor. Hay que entender la palabra complejo en su sentido literal: complexus: lo que se ha tejido junto. El amor es como un tapiz tejido con hilos muy diversos y de orígenes diferentes. Detrás de la unidad evidente de un "te quiero" hay una multiplicidad de componentes, y es precisamente la asociación de esos componentes tan diversos lo que constituye la coherencia del "te quiero" (Morin, 1997, p. 1).

Esto quiere decir que el amor tiene un gran número de propiedades que se unen para formar el todo. No se puede tomar sólo una parte del concepto para describirlo, como lo hicieron los invitados del Banquete, porque no estaría completo.

\section{Problemas similares}

Así como los participantes del "Banquete" dieron una definición personal y específica al concepto de amor, en el texto "Aesthetics" Jimenez (2014), muestra que cada filósofo hizo lo mismo para 
definir el concepto de Estética. Autores como Alexander Gottlieb Baumgarten, Immanuel Kant y Georg Wilhelm Friedrich Hegel formulan una definición del concepto de estética, enfocándose en as- pectos específicos. Sin embargo, al igual que en el Banquete, esas definiciones resultaron incompletas y difíciles de utilizar en diferentes idiomas y países, complicando la delimitación de este campo de conocimiento.

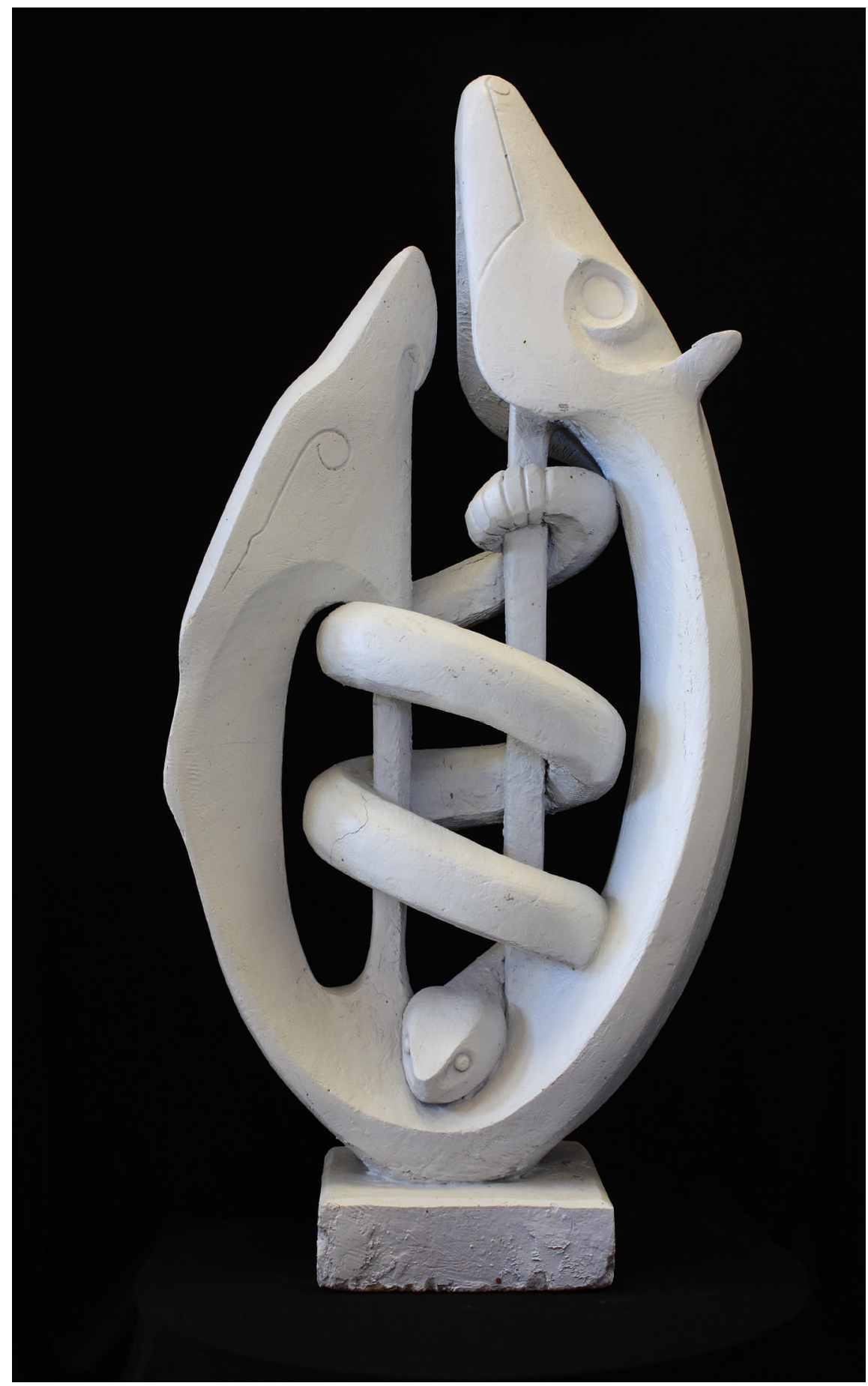

\section{¿Por qué el amor es un tema complejo?}

Los textos del "Banquete" y de "El complejo de amor" proveen ejemplos de cómo el amor se encuentra de cierta manera en un balance. Diotima dice que el amor está entre lo bueno y lo malo, entre lo bello y lo feo. Este se encuentra entre la carencia y la opulencia, debido a su origen de un padre sabio y rico, y de una madre ni sabia ni rica. De la misma manera, en "El complejo de amor" se menciona que el "amor cobra forma en el encuentro de lo sagrado y lo profano, de lo mitológico y lo sexual" (Morin, 1997, p. 2). Esto nos lleva a lo que dijo Diotima. Ella dijo que el amor era un demonio que se encontraba entre el cielo y la tierra. También se menciona que el amor es "el colmo de la unión de la locura y la sabiduría" (Morin, 1997, p. 4). Así, podemos decir que el amor está en un lugar intermedio y posee aspectos contrastantes. Se puede considerar que esto se refiere a las locuras que se pueden cometer cuando 
uno está enamorado y a la sabiduría que se adquiere al aprender las ideas de la otra persona o a la manera de tomar decisiones prudentes cuando se actúa por la persona amada.

Entonces, en el momento del amor estamos sometidos a una doble posesión, que viene mucho más lejos que nosotros mismos, que nos rebasa. La primera posesión es la del ciclo de reproducción que súbitamente nos invade y nos posee y que nosotros poseemos también y que podríamos llamar el deseo. La otra posesión es la que nace de lo sagrado, de lo divino, de lo religioso. La posesión física que viene de la vida sexual se encuentra con la posesión psíquica que viene de lo mitológico. Este es el problema del amor: somos doblemente poseídos y poseemos lo que nos posee (Morin, 1997, p. 2).

De la cita anterior es posible inferir dos tipos de amor, como lo decía Pausanias en el texto del Banquete. Se menciona la parte física, que se refiere al deseo y la atracción hacia una pareja, y la parte emocional, que forman parte del concepto general del amor hasta la actualidad.

La cuestión del amor se resume en esta posesión recíproca: poseer lo que nos posee. Somos individuos producidos por procesos que nos precedieron; estamos poseídos por cosas que nos sobrepasan y que van más allá de nosotros, pero, en cierta manera, somos capaces de poseerlos (Morin, 1997, p. 4).

Hablando de la sensibilidad contemporánea, esta frase se relaciona con las preguntas ¿cómo poseo la época? y ¿cómo la época me posee a mí? Éstas preguntas y la frase de los textos explican que nues- tro entorno nos afecta e influye, pero al mismo tiempo podemos tomar la decisión de enfrentar ciertas situaciones y realizar cambios que influyan en el futuro.

\section{¿Por qué la Estética es tan compleja como el amor?}

Así como con el amor, en el texto "Aesthetics" (Jimenez, 2014), señala varios aspectos que se deben de tomar en cuenta al momento de definir el campo de la Estética.

El traductor debe asegurarse del campo cubierto por "la estética" genérica. Él tiene, más o menos, la opción entre "la filosofía del arte," "la filosofía de lo bello", "la teoría del gusto," "la teoría del arte," "la teoría de las bellas artes," "la teoría" o "la ciencia" o "la crítica de lo bello," "la teoría o la ciencia del arte," sin mencionar algunos de sus equivalentes cercanos de otras lenguas, como théorie des beauxarts, Wissenschaft vom Schönen, Kunstlehre, Kunstkritik, o Kunstwissenschaft $^{2}$ (p. 16).

La estética se ha considerado una disciplina filosófica y teórica, que forma parte de otra más general. Por esta razón, ha resultado bastante complicado el poder especificar exactamente cuáles campos se pueden considerar dentro de la estética, es decir hasta dónde llegan los límites de esta, o qué áreas de conocimiento se deberían incluir en una definición precisa de dicha disciplina.

La misma preocupación con la diferenciación de los ámbitos de conocimiento que caen dentro de la estética incita a los filósofos del siglo veinte a especificar la naturaleza y orientación de su trabajo. "La estética" así pierde su carác- 
ter relacional e interdisciplinario, balanceándose entre las diferentes ciencias humanas, y llega a significar más bien una especie de meta-teoría o meta- discurso generalista y referencial ${ }^{3}$ (Jimenez, 2014, p. 16).

Esto demuestra que, al igual que el amor, la estética es un concepto complejo que no se puede definir sin tomar en cuenta todos los componentes que lo conforman.

\section{Otras relaciones}

El texto de "El complejo de amor" también está relacionado a otra figura que participó en el "Banquete". Algunas de sus ideas concuerdan con las del médico Erixímaco. Morin (1997), señala, "pero precisamente, lo que es la fuente de la verdad más grande es al mismo tiempo la fuente del error más grande. Por eso el amor es tal vez nuestra religión más verdadera y al mismo tiempo nuestra enfermedad más verdadera". Aquí, el autor utiliza la metáfora empleada por Erixímaco, en donde compara el estar enamorado con la enfermedad. (Platón 2005).

Esto se puede ver de dos maneras hoy en día. Cuando alguien está enamorado, puede actuar sin pensar y cometer locuras. Aquí se podría considerar una enfermedad mental. De igual manera, cuando un adolescente está enamorado puede hasta perder el apetito y el sueño. Esta también se puede considerar una enfermedad por algunos, pero en este caso sería física.

\section{Conclusiones}

Como sujeto contemporáneo con una sensibilidad contemporánea puedo ver un panorama más amplio, para darme cuenta de que el amor no se puede explicar de un sólo punto de vista, ya que es un concepto complejo que se debe analizar de diferentes ángulos. También, puedo concluir que la Estética se debe examinar de la misma manera para tener una definición más precisa.

Además, se puede decir que Diotima del "Simposio (Banquete) o de la erótica ", Edgar Morin autor de "El complejo de amor" y Marc Jimenez autor de "Aesthetics", pese a que pertenecieran a diferentes épocas, pensaron de la misma manera y en mi opinión estuvieron en lo correcto al decir que los conceptos mencionados anteriormente, el Amor y la Estética, son amplios y complejos.

Notas:

${ }^{1}$ Sigo aquí, la ideas de Girogio Agamben, sobre "sujeto contemporáneo" y de Adolfo Sánchez Vázquez, sobre "sensibilidad contemporánea".

${ }^{2}$ La traducción es mía.

${ }^{3}$ La traducción es mía.

\section{Bibliografía}

Agamben, G. (2011). Desnudez (M. Ruvituso, M. D’Meza y C. Sardoy, Trads. 1a ed. Vol. 427). Buenos Aires: Adriana Hidalgo editora.

Jimenez, M. (2014). Aesthetics (S. Rendall, C. Hubert, J. Mehlman, N. Stein y M. Syrotinski, Trads.). En B. Cassin (Ed.), Dictionary of Untranslatables. A Philosophical Lexicon (1a ed., pp. 14-17). United Kingdom: Princeton University Press.

Morín, E. (1997). El complejo de amor. Vuelta, 248, 11-14.

Platón. (2005/1962). Diálogos (29 ed. Vol. 13A). México: Porrúa.

Sánchez Vázquez, A. (1992). Invitación a la estética (1ạ. ed.). Grijalbo: México. 